\title{
Indicators of Utilization of Insecticide Treated Nets (ITNS) in Malaria Control and Elimination in Under-Fives in A Fast-Developing Urban Fringe in South-South Geographical Zone, Nigeria
}

\author{
Atting IA ${ }^{1 *}$, Ndon $\mathrm{EA}^{2}$, Afia $\mathrm{UU}^{3}$, Ekuma $\mathrm{AE}^{1}$, Atting $\mathrm{MI}^{4}$ and Ekanem $\mathrm{AM}^{5}$ \\ ${ }^{1}$ Department of Medical Microbiology and Parasitology, Faculty of Basic Clinical Sciences, \\ College of Health Sciences, University of Uyo, Nigeria \\ ${ }^{2}$ Center for Wetlands and Waste Management Studies, Faculty of Agriculture, University of \\ Uyo, Nigeria
}

${ }^{3}$ Department of Animal and Environmental Biology, Faculty of Science, University of Uyo,

Nigeria

${ }^{4}$ Maritime Academy of Nigeria (MAN), Oron, Nigeria

${ }^{5}$ Department of Community Health, Faculty of Clinical Sciences, College of Health Sciences, University of Uyo, Nigeria

*Corresponding author: Atting IA, Malaria (IVM), NTDs and Vector-borne Parasitic Diseases Research Unit, Department of Medical Microbiology and Parasitology, Faculty of Basic Clinical Sciences, College of Health Sciences, University of Uyo. Akwa Ibom State, Nigeria, Email: dr_atting@yahoo.com

\section{Abstract}

Malaria still remains an important public health concern in most parts of the world. Insecticide treated nets (ITNs) have been found to be one of the most cost effective and inexpensive specific control measures of preventing malaria. The study aimed at the assessment of malaria parasitemia under five-year-old children, awareness, accessibility, availability, and utilization of Insecticide Treated Nets (ITNs) in the control and elimination of malaria in under five-year-old children (under-fives) in Ikot Ekpene, Nigeria. Blood samples were taken from a total of 450 under-fives in 250 randomly selected households and screened for malaria parasites using thin/thick blood film method. Pre-tested structured questionnaires were administered to heads of selected households. Descriptive statistics were used in analyzing the data obtained based on the stated objectives. Analysis of the blood samples showed that the prevalence of Plasmodium falciparum malaria parasitemia in under-fives was $64.4 \%$ overall and $57.1-69.2 \%$ among the clans in the study area. The study also revealed relatively high awareness, accessibility, availability, and affordability of ITNs but low utilization of ITNs in the study area, which was attributable to some negative beliefs by the respondents. This study shows that there is a high level of malaria parasitemia among under five children in the study area in spite of high ownership of insecticide treated bed nets suggesting that there may not be proper use of insecticide treated nets for children of this age group. Interventions in this area should include strategies to encourage proper use of insecticide treated nets.

Keywords: Malaria; Insecticide Treated Nets (ITNs); Utilization; Indicators; Under-fives

\section{Introduction}

Malaria is a common but a serious tropical infection and one of the oldest diseases known to mankind. Even one hundred years after its recovery, malaria still remains an important public health concern all over the world. More than three quarters of global malaria deaths occur in underfive years old children (under-fives) in countries in sub- 
Saharan Africa [1], and $25 \%$ of all childhood mortality below the age of five (about 800,000 young children) is attributable to malaria [2]. And of those children who survive cerebral malaria (a severe form of the disease) more than 15\% of them often suffer neurological defects characterized with weakness, partial blindness, speech problems and epilepsy and where such children are properly managed or have access to specialized education and good medical care, it may interfere seriously with their future learning and development [3]. The disease is also associated with 1.1 to 2.2 million deaths annually in the world, and out of that about 1 million are under-five year old children in the affected areas. It is also the major cause of infant mortality and the only insect-borne parasitic disease comparable in impact to the world's major killer transmissible diseases [4].

Every year, an estimated 300-500 million clinical cases of malaria occur making it one of the most common infectious diseases globally [5] including Ikot Ekpene LGA in Akwa Ibom State of Nigeria. Malaria constitutes $10 \%$ of the continent's overall disease burden, accounting for $40 \%$ of public health expenditure, $30-50 \%$ of in-patient hospital admissions, and up to $50 \%$ of out-patient visits in areas affected with high transmission [6]. The under-fives and pregnant women are particularly vulnerable to the disease because of undeveloped immunity in them and reduce immunity due to psychological changes that normally takes place in a women during pregnancy respectively. Malaria often contributes to neonatal and maternal mortality, and also causes low birth weight in infants.

In Nigeria, malaria is the leading cause of mortality in under-fives, contributing 33\% of all childhood deaths and $25 \%$ infant mortality. When children are typically sick of malaria between 3-4 times in one year, it becomes a major disease which usually leads to long absenteeism from school, thus impeding their educational and social development and subsequently robbing the country of its future human resources [7]. The malaria situation in Ikot Ekpene Local Government Area of Akwa Ibom State is not different, the disease ranks highest among the endemic notifiable diseases, and its transmission is throughout the year with more prevalence during rainy season, and stagnant water provides suitable habitat for the breeding of the larvae of mosquito vector of the disease. In addition, the area being a tropical and industrial zone is prone to malaria transmission especially in the urban fringe clan due to overcrowding of the population, which results in poor living environment. This in turn, results in indiscriminate waste disposal, etc. that attracts the breeding of the vector which leads to greater transmission of the disease in the study area.

Globally, and especially in Nigeria, the efficacy of malaria drugs for its treatment and insecticides used for the control of the disease vector are being threatened due to malaria parasite resistance to anti-malaria drugs and the emergence of mosquito vector resistance which leads to an increased incidence of the disease, including gross infant anemia. Several global and regional attempts have been made at controlling the disease in the past with little success as a result of ineffective strategies used, and insufficient resources [8]. Insecticide treated nets (ITNs) has been found to be one of the most cost effective and inexpensive specific control measures of preventing malaria. This has been proven universally with the capacity to reduce malaria burden significantly [9]. Its other associated benefits are, improved growth and weight gain in infants; reduced maternal mortality, placental malaria and maternal anemia, resulting in reduced risk of low birth weight [10].

Malaria control with ITNs in the prevention of infection has been recommended for adoption as an important component of the anti-natal clinic [11]. Insecticide treated nets (ITNs) have been shown to reduce the number of malaria episodes as much as $50 \%$, and childhood mortality by $20 \%$ [12]. Therefore, promoting its use can be a key approach towards the reduction of morbidity and mortality among the most at risk. In April, 2000 African Heads of State met in Abuja, Nigeria where they set among other targets in the Roll Back Malaria (RBM) Programme, a $60 \%$ use of ITNs among the vulnerable groups (under-fives, pregnant women and the aged), by the year 2005. That is, to ensure that they have access to sleep under insecticide treated nets (ITNs). At this historic Malaria Summit, African Heads of State made a declaration to bury the burden of malaria by the year 2010 [13].

Also, recently, all continents endemic with malaria are strengthened to scaling up ITNs distribution with particular reference to these groups in all malaria endemic areas, and this has been widely promoted as a means of preventing manvector contact in the control of malaria [7]. Net ownership is an important instrument used in assessing the effectiveness of the distribution channels of the RBM programme, it aids in offering useful suggestions where there are lapses. Equity is also a major issue in ITNs' ownership though generally found to be low among the poorest households universally. In order to increase access to ITNs, certain perception concerning ITNs' use, the cost and the chemical used for its treatment must be seriously handled by providing important lessons for malaria programme that aims at assessing utilization of ITNs among mothers [5].

Previous studies carried out on utilization of ITNs by other researchers revealed various factors influencing ITNs use to include cultural, behavioural and demographic factors, ethnicity, accessibility, gender relations and seasonality of malaria $[14,15]$. The researchers pointed out that, even if 
ITNs are purchased and used correctly, its local acceptance may still be influenced by the assumed toxicity from chemical used in its re-treatment. The present study aimed to ascertain the prevalence of malaria in under-fives, assess the availability, accessibility and utilization of Insecticide Treated Nets (ITNs), and malaria control in this vulnerable age group in an Urban Fringe in Ikot Ekpene Local Government Area, Akwa Ibom State, Nigeria.

\section{Methodology}

\section{Study Location}

This study was conducted in Ikot Ekpene, Amayam, and Otoro Uboe clans of Ikot Ekpene Local Government Area of Akwa Ibom State, South-south Nigeria.

\section{Instrument Used for Data Collection and Study Sample}

Pre-tested structured questionnaire prepared by the researchers was administered to selected heads of households or their representatives (in their absence). A total of 250 questionnaires were distributed among the selected household heads or their representatives. Additional information was gathered through a total of three Focus Group Discussions (FGDs) that were held in the study area with separate groups of men, women and youths comprising at least nine members in each session. A total of 450 underfives from the randomly selected households in the study area were screened for malaria parasite. Every under-five in the selected households had their blood sample taken from their finger thumbs for the malaria screening. Any household without under-five was not sampled.

\section{Screening for Malaria Parasite}

Households were randomly selected from the three communities studied. Every under-five in the selected households was screened for malaria parasites in their blood samples. These were later taken to the laboratory for analysis.
A total of 450 blood samples were considered for malaria parasite examination. Each blood sample was screened for malaria parasites by using the thick film method.

\section{Thick Film Method}

Thick blood films were prepared as described by Ersley, et al. It was later stained with 1:10 dilution of Giemsa solution and air dried. The slide was gently washed with few drops of distilled water, and air dried again for few minutes, and examined under x10 oil immersion objective microscopic lens to determine the presence or absence of Plasmodium species. The film was considered to be positive with malaria parasite, if there were presence of the ring form trophozoites or any other blood stage of erythrocytic schizogony detected. A film is also considered negative, if no parasite was seen after scanning for at least 100-200 fields.

\section{Statistical Analysis}

Descriptive statistics such as frequency counts, percentages and ranks were used in analyzing the set objectives of the study. The chi-square analysis was used to assess the association between respondents' knowledge of the cause of malaria and the utilization of Insecticide Treated Nets (ITNs) for under-fives. The chi-square analytical technique was also used to ascertain the association between the respondents' knowledge of the mode of transmission of malaria to man and utilization of ITNs for under-fives in Ikot Ekpene Local Government Area.

\section{Results}

\section{Malaria Parasitemia in Under-Fives}

A total of 450 children aged five years and below were recruited in this arm of the study out of which 200 were males. The number of malaria positive children were 180 (69\%), 80 (57\%), and 30 (60\%) from Ikot Ekpene, Amayam and Otoro Uboe Clans, respectively (Table 1).

\begin{tabular}{|c|c|c|c|c|c|c|c|}
\hline \multirow{2}{*}{ Study area } & \multirow{2}{*}{ No. Examined } & \multirow{2}{*}{ No. Infected } & \multicolumn{2}{|c|}{ Gender } & \multicolumn{2}{c|}{ No. } & \multicolumn{2}{c|}{ Gender } \\
\cline { 4 - 8 } & & Male (\%) & Female (\%) & Uninfected & Male (\%) & Female (\%) \\
\hline $\begin{array}{c}\text { Ikot Ekpene } \\
\text { Clan }\end{array}$ & 260 & $180(69)$ & $62(34)$ & $118(66)$ & $80(31)$ & $50(62)$ & $30(38)$ \\
\hline Amayam Clan & 140 & $80(57)$ & $30(38)$ & $50(62)$ & $60(43)$ & $24(40)$ & $36(60)$ \\
\hline Otoro Uboe Clan & 50 & $30(60)$ & $18(60)$ & $12(40)$ & $20(40)$ & $12(60)$ & $8(40)$ \\
\hline Total & 450 & $290(64)$ & $110(38)$ & $180(1.8)$ & $160(36)$ & $90(56)$ & $70(44)$ \\
\hline
\end{tabular}

M - Male F - Female

Table 1: Prevalence of under-fives infected with malaria parasites in the study area. 


\section{Journal of Quality in Health care \& Economics}

\section{ITN Utilization Survey}

The survey questionnaire was administered to 250 individuals across the 3 communities. There were 39 (15.6\%) participants who admitted to having no ITNs in their households while 20 (8\%) said there were more than 5 ITNs in their households. Most participants (53.1\%) said they got their ITNs from government hospitals, while $12.8 \%$ obtained theirs from house to house distribution by health workers. Most respondents $(48,8 \%)$ said that ITNs were mainly used by children under 5 years followed by (14.8\%) who said they were mainly used by pregnant women and $11.2 \%$ who said they were mainly used by older children (Table 2 ).

\begin{tabular}{|c|c|c|}
\hline Number of ITNs owned by Respondents & Frequency (n) & Percent (\%) \\
\hline None & 39 & 15.6 \\
\hline $1-5$ & 191 & 76.4 \\
\hline Above 5 & 20 & 8 \\
\hline Source of obtaining ITNs & 112 & 53.1 \\
\hline Government Hospitals/ Clinics & 27 & 12.8 \\
\hline House-house distribution by Health workers & 21 & 10 \\
\hline Bought from Private Clinics & 19 & 9 \\
\hline Bought from shop/ market vendors/ community ITNs sellers & 20 & -9.5 \\
\hline Others & 12 & -5.6 \\
\hline
\end{tabular}

Table 2: Study participants' access and utilization of Insecticide Treated Nets (ITNs).

The Table 3 results show that, greater number (46.8\%) of under-fives who suffered from malaria are being diagnosed by medical doctors in the hospitals/ clinics as compared to $5.6 \%$ being diagnosed by others such as friends, family members or neighbors.

\begin{tabular}{|c|c|c|}
\hline Who diagnosed children of malaria & Frequency & (\%) \\
\hline In Hospitals/ Clinics by Medics & 117 & 46.8 \\
\hline Other Health Workers in Hospitals/ Clinics & 57 & 22.8 \\
\hline Traditional Birth Attendants (TBAs) at home & 36 & 14.4 \\
\hline Parents of the under-fives & 26 & 10.4 \\
\hline Others (Neighbors/ family members/ friends) & 14 & 5.6 \\
\hline
\end{tabular}

Table 3: Sources of malaria diagnoses by study participants.

According to Tables $3 \& 4$, while most participants sought malaria diagnosis from hospitals, a significant number

sought opinions from unqualified community members.

\begin{tabular}{|c|c|c|}
\hline & Frequency(n) & Percentage (\%) \\
\hline \multicolumn{3}{|l|}{ Major causes of malaria } \\
\hline Mosquito Bites & 147 & 58.8 \\
\hline Unsanitary environment & 56 & 22.4 \\
\hline Too much palm oil in the meal & 40 & 16 \\
\hline Mid-day sunshine/ sunlight & 7 & 2.8 \\
\hline \multicolumn{3}{|l|}{ Methods of prevention/ control of malaria } \\
\hline By using anti-malarial drugs & 49 & 19.6 \\
\hline By sleeping under ITNs & 52 & 20.8 \\
\hline By wearing protective clothes such as trousers, long sleeves, etc. & 10 & 4 \\
\hline By using insecticides & 28 & 11.2 \\
\hline By always keeping one's environment clean & 75 & 30 \\
\hline Others (using "Dongoyaro" leaves and keeping in tune with the gods of the land) & 36 & 14.4 \\
\hline
\end{tabular}

Table 4: Study participants' opinions on cause and prevention of malaria. 
On the cause of malaria, $58.8 \%$ of participants were aware that mosquito bites were the cause, but $22.4 \%$ thought it was due to unsanitary environment, $16 \%$ to too much palm oil and $2.8 \%$ to sunshine. On methods of preventing malaria, $30 \%$ selected keeping environment clean, followed by sleeping under ITNs (20.8\%) and using antimalarial drugs (19.6\%).

\section{Discussion}

This study revealed that over half of children surveyed had parasitemia.in this population. Previous studies have found lower rates in Calabar and elsewhere [16]. Although several studies have shown that detectable parasitemia is associated with a lower risk of symptomatic malaria and therefore important in maintaining protective immunity suggesting that treating them might predispose to more severe infections, a recent study has shown that treatment of asymptomatic infections was not associated with an increased risk of symptomatic malaria [17].

While most participants said they sought diagnosis and treatment from governmental health institutions, it is worrying that a sizeable number of participants still sought diagnosis and treatment from traditional attendants and neighbours. The high confidence in diagnoses and treatment in hospitals may be a result of the free health care policy for under-fives in Akwa Ibom State. Studies have shown that cultural and religious beliefs among caregivers affect their health seeking behavior $[16,18]$. This was consistent with the findings of this study. Cultural factors must be considered in strategies for malaria prevention and treatment to achieve high acceptance rates in communities.

The great majority of respondents said they had ITNs in their households. High levels of ITN ownership in communities have been attributed to level of education, wealth index, family size among other factors [19]. Nonetheless, ITN ownership does not always correlate with bed net use nor does good knowledge of malaria prevention $[20,21]$. This possibility could be corroborated by the high prevalence of malaria parasitemia among children surveyed in this study. For the remaining percentage of respondents without ITNs, more aggressive house-to-house distribution may be required to reach them as this approach was not one of the most common sources for respondents. Several studies in different parts of Nigeria have shown moderate to dramatic increase in ITN ownership where there have been ITN distribution campaigns [23-45].

On the assessment of utilization of ITNs in the selected households with under five years old children in malaria endemic area of Ikot Ekpene LGA, it was crucial to understand the respondents' behavior and attitude towards the actual usage of ITNs, for example, facts from several studies revealed some negative behavior of respondents toward ITNs use despite the increasing provision of free nets [46-51]. Some respondents, precisely mothers, were not using ITNs for their original purpose, for example some instead of using it on their under five years old children while sleeping, rather use it to cover their vegetable gardens, others use it as filter and so on. This shows that most of the mothers do not appreciate the usefulness of ITNs at all and when demonstrated to them on how to hang it by health workers. Instead of appreciating it, some mothers gave some flimsy excuses. This is because their minds were still set at traditional medicines, fetish beliefs that those nets cannot prevent or control malaria [52-59].

\section{Conclusion}

This study shows that there is a high level of malaria parasitemia among under five children in Ikot Ekpene in spite of high ownership of insecticide treated bed nets suggesting that there may not be proper use of insecticide treated nets for children of this age group. This finding will definitely impair the attainment of the ambitious goals for reduction in case incidence and death rates of at least $90 \%$ by 2030 , a strategy set by WHO and adopted by the World Health Assembly (WHA) in May 2015. Interventions in this area should include strategies to encourage proper use of insecticide treated nets.

\section{References}

1. Roll Back Malaria (2007) Framework for Monitoring Progress and Evaluating Outcomes and Impact. pp: 1-30.

2. Rowe RW, Stekette RW, Rowe SY, Snow RW (2000) Estimates of the burden of mortality directly attributable to malaria for children under 5 years of age in Africa for the year.

3. Samba E (2001) The Malaria Burden and Africa. American Journal of Tropical Medicine and Hygiene. 64(1-2S).

4. WHO (1990) The Clinical Management of Acute Malaria. WHO Regional Publications, South-East Asia Series, New Delhi, pp: 941.

5. World Malaria Report (2005): World Health Organisation and UNICEF.

6. Federal Ministry of Health (FMOH) (1989 and 1990). Guidelines for Malaria Control for Primary Health Care Workers in Nigeria. Federal ministry of health, Lagos.

7. RBM (Roll Back Malaria) (2002). Scaling up insecticidetreated nets (ITNs) Programmes in Africa: a strategic 
framework for coordinated national action. Geneva: Roll back Malaria, Technical Support Network for InsecticideTreated Materials 2000. pp: 68.

8. TerKuile FO (2003) Impact of Permethrin-treated Bed nets on Malaria and all-cause morbidity in young children in an area of Intense Perennial Malaria Transmission in Western Kenya: cross-sectional survey. American Journal of Tropical Medicine and Hygiene 68(4S): 100-107.

9. Lengeler C, Armstrong Schellenberg J, Alessandro UD, Binka F, Cattani J (1998) Relative versus absolute Risk of dying Reduction after using Insecticide Treated Nets for Malaria Control in Africa. Trop Med Int Health 3: 286290.

10. TerKuile FO, Terlouw DJ, Kariuki SK (2003) Impact of Permethrin Impregnated Bed Nets on Malaria Anemia, and Growth in infants in an area of intense Perennial Malaria Transmission in Western Kenya. American Journal of Tropical Medicine and Hygiene 68(S4): 68-77.

11. Ansell J, Hamilton K (2004) Short range attractiveness of Pregnant Women to Anopheles Mosquitoes. Transactions of Royal Society of Tropical Medicine and Hygiene 96(2): 113-166.

12. Noor AM, Amin, AA, Akhwale WS, Snow RW (2007) Increasing coverage and decreasing inequity in insecticide-treated bed net among rural Kenyan children. PLOS Med 4: e255.

13. Welcome Trust, Malaria Risk (2008) Nigeria Malaria status in World malaria report pp: 66-101.

14. Heggenhougen HK, Hackenthal V, Vivek P (2003) Bed Net Usage and its Acceptance at the Local Level. Chapter 6 In: The Behaviour and Social Aspects of Malaria Control: An Introduction and Annoted Biography. Geneva: Special Programme for Research and Training in Tropical Diseases (TDR), World Health Organization, pp: 97-106.

15. Winch PJ, Makemba AM, Makame VR, Mfaume MS, Lynch, et al. (2007) Social and Cultural factors affecting rates of regular retreatment of mosquito nets with insecticide in Bangamoyo district, Tanzania. Tropical Medicine and International Health 2: 760-70.

16. Iwuafor AA (2016) Malaria Parasitaemia and the use of insecticide-treated nets (INTs) for malaria control amongst under-5 year old children in Calabar, Nigeria', BMC Infectious Diseases. BMC Infectious Diseases 16: 151.

17. Portugal S (2017) Treatment of Chronic Asymptomatic Plasmodium falciparum Infection Does Not Increase the Risk of Clinical Malaria Upon Reinfection, Clinical Infectious Diseases 64: 645-653.

18. Lars O, Elverdan B (2000) Malaria in the United Republic of Tanzania: cultural considerations and health-seeking behaviour. Bulletin of the World Health Organization 78(11): 1352-1357.

19. Stratton L (2008) The persistent problem of malaria: addressing the fundamental causes of a global killer. Soc Sci Med 67(5): 854-862.

20. Ahmed SM, Zerihum A (2010) Possession and Usage of Insecticide Bed Nets among the People of Uganda: is BRAC Uganda Health Programme pursuing a proppoorpath. Plos One pp: 5.

21. National Population Commission and ORC Macro (2003) Nigeria Demographic and Health Survey, NDHS. Abuja, Nigeria.

22. National Population Commission (2004) Federal Republic of Nigeria: Nigeria Demographic and Health Survey 2003 Calverton, Maryland.

23. Daboer JC, Chingle MP (2010) Malaria Parasitaemia and Household use of Insecticide Treated Bed Nets: a crosssectional survey of under-five in Jos, Nigeria. Nigerian Medical Journal 51(1): 5-9.

24. Ashikeni MA, Envuladu EA, Zoakah AI (2013) Malaria and the use of the Insecticide Treated Net (ITN) among under-five children in Kuje Area Council of the Federal Capital Territory Abuja, Nigeria. International Journal of Mosquito Research 3(6): 45-53.

25. Oresanga, Olusola B., Hoshan, M, Sofola OT (2008) Utilization of Insecticide Treated Net by Under five years' children in Nigeria. Assessing Process towards the Abuja targets Malaria Journal 7: 145.

26. Abebe A, Gebre_Michael T, Meclhum G, Balkew M, Boshay S, et al. (2008) Assessment of Distribution Knowledge and Utilization of Insecticide Treated Nets in Selected malaria prone Area of Ethiopia. Ethiopia Journal of Health Development 22(3): 268-274.

27. Alali JA, Hawley WA. Kolczak MS (2003) Factors affecting use of Premethrin-treated Bed Nets during a Randomized Conttrolled trail in West Kenya, Am J Trop Med Hyg 68: 137-141.

28. Almedi HE, Zhou G, Afrane Y, Lee MC, Mwanzo I (2001) Insecticide- treated net (ITN) Ownership, usage and Malaria Transmission in the highlands of Western Kenya. Parasite Vectors 4: 113. 
29. Aygepong IA, Manderson L (1999) Mosquitoes Avoidance and Bed Net use in the Greater Area Region, Ghana, J Biosocial Sci pp: 79-92.

30. Bennett P, Smith C (2002) Parents Attitudinal and Social Influences on Childhood vaccination. Health Education Research (7): 341-348.

31. Binka FN, Adongo P (1997) Acceptability and use of Insecticide Impregnated Bed Nets effects on Resting and Feeding Behaviour of Lymphatic Filariasis Vector Mosquito in Kenya Med Vet Entomol 12: 52-59.

32. Binka FN, Adongo P (1997) Acceptability and use of Insecticide Impregnated Bed Nets in Northern Ghana, Trop Med Int Health 2: 499-507.

33. Bruce Chwatt LJ (1998) Malaria in Nigeria. Med Hys 45(4): 73.

34. Chukwuocha, DOzie LNS, OnwuhnCoC, Ukaga CN; Nwoke BEB, et al. (2010) Perception on the use of Insecticide Treated Nets in parts of Imo River Basin, Nigeria; Implication of Preventing malaria in Under five years old children. African Health Journal 14(1): 117-128.

35. Chwatt LJ (1985) Essential Malariology. $2^{\text {nd }}(E d n$.$) ,$ London: William Heinemann Medical Books Ltd. pp: 6570 .

36. D'alessndro U, Olaleye BO, McGuire W, Langerock P (1995) Mortality and Morbidity from Malaria in Gamain Children after Introduction of an Impregnate Bed Net Programme. Lancet 345: 479-483.

37. Edalu BO, Ikefuna AN, Emodia SI, Adimora GN (2010) Awareness of use of Insecticide treated bed nets among children attending outpatient clinic at UNTH, Enugu. The need for effective mobilization process. African Health Science 10 (2): 117-419.

38. Ganiyu AS, Robin O J (2010) Awareness and use of Insecticides treated nets among women attending antenatal Clinic in a Northern State of Nigeria. Journal of Medical Health 24: 16-28.

39. Guyatt HL, Ochola SA, Snow RW (2004) Use of Intermittent Presumptive Treatment and Insecticidetreated bed nets by Pregnant Women in four Kenya Districts. Trop Med Int Health 9: 255-261.

40. Hornby AS (2001) Oxford Advanced Learners Dictionary $7^{\text {th }}($ Edn.).

41. Iyaniwura CA, Ariba A, Runsewe Abiodun T (2008) Knowledge, use and promotion of insecticide treated nets by health workers in a suburban town in south western Nigeria. Nig J Clin Pract 11: 149-154.

42. Laura RS, Noel SW, Pau EB, Barba AR, Sarah GS, et al. (2012) Determinant of use of Insecticide-Treated Nets for the Prevention of Malaria in pregnancy: Jinja Uganda. Plos One 7(6): L73-93.

43. Lengeler C (2004) Insecticide-treated bed nets and Curtains for Preventing Malaria. Cochrane Database System Review 2: CD000363.

44. Lengeler C, Snow RW (2000) From Efficacy to effectiveness of Insecticide-treated bed bets in Africa. Bulletin of the World Health Organization 74: 325-332.

45. Macdonald G (1992) The Epidemiology and Control of Malaria, London: Oxford University press pp: 35.

46. National Population Commission (2003) Federal Republic of Nigeria: Nigeria Demographic and Health Survey 2003 Calverton, Maryland.

47. NetMark (2001) Baseline Survey on the Use of Insecticide Treated Malarial in Nigeria.

48. Nevill C, Some E, Mung'ala V, Mutemi W, New L, et al. (1996) Insecticide-treated bednets reduce mortality and severe morbidity from severe malaria children on the Kenyan Coast. Trop Med Int Health 1(2): 139-146.

49. Obionu N (1997) Knowledge and Practice of Injection Safety among Workers of Nigerian Prison Service Health Facilities in Kaduna State. Primary Health Care, Ezu book Ltd, Enugu. pp: 1-21.

50. Pearson B (2007) WHO Issues Guidance for Insecticide Treated Mosquito Nets (News) African health.

51. Sexton JD, Ruebush TK, Brandling Bennett A D (1990) Permethrin Impregnated Curtains and Bed Nets Prevent Malaria in Western Kenya. American Journal of Tropical Medicine and Hygiene 43: 11-18.

52. Snow RW, Guyatt HL (2001) The Epidemiology and burden of Plasmodium falciparum-related anaemia among pregnant women in sub-Saharan Africa. American Journal of Tropical Medicine and Hygiene 64(1-2S): 3444.

53. Snow RW, Rowan KM, Lindsay SW, Greenwood BM (1988) A trial of bed nets (mosquito nets) as a malaria control strategy in a rural area of the Gambia. West Africa, Transactions Royal Society of Tropical Medicine and Hygiene 82: 212-225.

54. WHO (2002) The Roll Back Malaria Partnership Roll Back Malaria. 
55. WHO and UNICEF (2003) Africa Malaria Day Report.

56. WHO World Malaria Report (2011).

57. WHO (1993) World Malaria Situation. Weekly Epidemiology Record.
58. WHO (1986) Expert Committee on Malaria. Eighteenth Report. Tech Rep Ser pp: 735.

59. Beljaev AE (1995) Malaria Situation in the WHO Eastern Mediterranean region. Med Parazitol (Mosk) (2): 12-15.

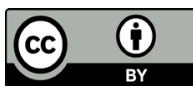

